\title{
Incidence and predictive factors of diaphragmatic dysfunction in acute stroke
}

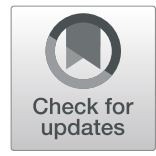

José Vicente Catalá-Ripoll1 ${ }^{*}$, José Ángel Monsalve-Naharro ${ }^{1}$ and Francisco Hernández-Fernández ${ }^{2}$

\begin{abstract}
Background: The most characteristic clinical signs of stroke are motor and/or sensory involvement of one side of the body. Respiratory involvement has also been described, which could be related to diaphragmatic dysfunction contralateral to the brain injury. Our objective is to establish the incidence of diaphragmatic dysfunction in ischaemic stroke and analyse the relationship between this and the main prognostic markers.

Methods: A prospective study of 60 patients with supratentorial ischaemic stroke in the first $48 \mathrm{~h}$. Demographic and clinical factors were recorded. A diaphragmatic ultrasound was performed for the diagnosis of diaphragmatic dysfunction by means of the thickening fraction, during normal breathing and after forced inspiration.

Diaphragmatic dysfunction was considered as a thickening fraction lower than $20 \%$. The appearance of respiratory symptoms, clinical outcomes and mortality were recorded for 6 months. A bivariate and multivariate statistical analysis was designed to relate the incidence of respiratory involvement with the diagnosis of diaphragmatic dysfunction and with the main clinical determinants.

Results: An incidence of diaphragmatic dysfunction of $51.7 \%$ was observed. $70 \%$ ( 23 cases) of these patients developed symptoms of severe respiratory compromise during follow-up. Independent predictors were diaphragmatic dysfunction in basal respiration $(p=0.026)$, hemiparesis $(p=0.002)$ and female sex $(p=0.002)$. The cut-off point of the thickening fraction with greater sensitivity (75.75\%) and specificity (62.9\%) was $24 \%$ ( $p=0.003$ ).

Conclusions: There is a high incidence of diaphragmatic dysfunction in patients with supratentorial ischaemic stroke which can be studied by calculating the thickening fraction on ultrasound. Among these patients we have detected a higher incidence of severe respiratory involvement.
\end{abstract}

Keywords: Stroke, Respiratory, insufficiency, Diaphragmatic paralysis, Ultrasound

\section{Background}

Acute stroke is the third most important cause of death and the most important cause of disability in Western countries [1, 2]. However, in recent years a reduction has been seen both in incidence and mortality due to the improved preventive and therapeutic measures taken [3].

\footnotetext{
* Correspondence: jose.catalaripoll@gmail.com

'Department of Anesthesiology and Critical Care Medicine, Complejo Hospitalario Universitario de Albacete, Albacete, Spain

Full list of author information is available at the end of the article
}

The motor and/or sensory involvement of one side of the body is the predominant clinical sign, though there are also respiratory disorders which for the moment are poorly characterised in the literature. These depend on the location and extent of the neurological injury [4]. They can be attributed to changes in respiratory mechanics due to involvement of the respiratory control centres or weakness of respiratory muscles [4]. They usually manifest as respiratory failure, atelectasis, lung infections or sleep disturbances [5-7]. Diaphragmatic dysfunction is another potential mechanism of respiratory impairment in stroke [8]. 
The diaphragm is responsible for performing from 60 to $80 \%$ of the inspiratory effort $[5,9,10]$. It shows bilateral innervation from the cervical plexus through two phrenic nerves that are formed from $\mathrm{C} 3$ to $\mathrm{C} 5$ roots $(\mathrm{C} 4$ probably to a greater extent) [11, 12]. Involvement of diaphragmatic muscles or the phrenic nerve can cause diaphragmatic dysfunction [13]. This dysfunction ranges from a partial loss of the ability to generate pressure due to muscle weakness to a full loss of diaphragmatic function due to palsy thereof [14]. Unilateral involvement of this muscle is usually paucisymptomatic [15], and may be an underdiagnosed cause of dyspnoea. On the contrary, the bilateral lesion leads to significant dyspnoea at rest, in particular in a lying-down-on-the-back (supine) position [16-18].

Involvement of the diaphragm in ischaemic stroke has been generally described as a palsy contralateral to the lesion in patients with hemiparesis $[1,5,6]$. A bilateral reduction in mobility has been also seen, with no direct diaphragmatic dysfunction, that can contribute to reducing respiratory function in these patients $[19,20]$. This diaphragmatic dysfunction could contribute to the appearance of respiratory failure [5] or other complications such as respiratory infections [1].

The ultrasonographic study of the diaphragm has been developed in recent years to evaluate the function of this muscle [21]. This technique provides a non-invasive method, independent of the effort of the patient, and allows images to be viewed in real time [17, 22, 23].

The objective of our study is to establish the incidence of diaphragmatic dysfunction measured by ultrasonography in a number of patients with acute ischaemic stroke. We have also analysed the relationship of this diaphragmatic dysfunction with the appearance of respiratory impairment (RI) and the main prognostic markers of stroke: vascular territory, clinical severity, degree of hemiparesis and administration of reperfusion treatments.

\section{Methods}

A prospective observational study in a cohort of cases diagnosed with acute ischaemic stroke. Patients diagnosed with supratentorial ischaemic stroke in the first $48 \mathrm{~h}$ of hospital admission to a stroke unit or critical care unit were selected from the period between 1 November 2017 and 1 May 2018.

The exclusion criteria were: infratentorial ischaemic stroke, patients not collaborating with the diaphragmatic ultrasonography, non-evaluable study of the thickening fraction (TF), use of maintained assisted ventilation in the first $48 \mathrm{~h}$ of hospital stay, and patients with a medical history that could interfere with diaphragmatic mobility, such as known previous diaphragmatic dysfunction, history of chest and upper abdominal surgery, previous chest injury and previous hemiparesis leading to significant functional limitation, defined by the mRS scale (Modified Rankin Scale) as 3 or higher.

In our site, patients are evaluated initially by an onduty neurologist and a baseline computerised tomography (CT) scan is performed, with administration thrombolytic treatment (alteplase) up to $4.5 \mathrm{~h}$ after onset, following the recommended guidelines of the Spanish Society of Neurology of 2014 [24]. In the cases where primary or rescue mechanical thrombectomy (MT) is considered, perfusion CT and angioCT of supra-aortic trunks and brain are performed beforehand. Imaging tests were performed in a Philips 64-detector multi-slice CT, Brilance model (Koninklijk Philips Electronics N.V., Amsterdam, Netherlands).

The images are analysed by a neuroradiologist, with MT considered in patients with large vessel occlusion (M1, M2, ICA, intracranial or in tandem, A1, P1, basilar) and time from onset of $8 \mathrm{~h}$ or less. Those with an indeterminate time from onset (for instance, stroke on awakening) are considered candidates for MT if they show a perfusion deficit consistent with mismatch of $30 \%$ or higher, as measured by perfusion CT. Patients undergoing MT are given general anaesthesia and are extubated systematically after the procedure. They are subsequently admitted to the Critical Care Unit and, if there are no incidents, they are referred to the Stroke Unit at $24 \mathrm{~h}$ post-MT. The rest of the patients with acute stroke, including those treated with alteplase, are admitted to the Stroke Unit in the first 24-72 h.

Data were collected from the medical records, including demographics, history of the patients: cardiovascular risk factors, functional classification according to the NYHA scale (New York Heart Association) and history of respiratory diseases [chronic obstructive pulmonary disease (COPD) or sleep apnoea-hypopnoea syndrome (SAHS)]. Clinical data were collected: aetiology of the stroke, vascular territory affected, NIHSS (National Institute of Health Stroke Scale), severe sensory aphasia defined as not understanding instructions, degree of hemiparesis (MRC scale, Medical Research Council), application of reperfusion therapies and their success measured by the TICI scale (Thrombolysis in cerebral infarction) or the TIBI scale (Thrombolysis in Brain Ischemia), as applicable.

A follow-up of 6 months after the event was carried out through two telephone calls (at 3 and 6 months). We obtained data on mortality, mRS at 3 months and respiratory involvement, defined as the occurrence of severe dyspnoea (grade 3-4 of the MRC scale), orthopnoea, respiratory infection and difficulty expectorating. To study the prognosis, mRS was dichotomized: good prognosis (score 0-2) and poor prognosis (score 3-6).

Ultrasound images were obtained with a portable Mindray TE7 ultrasound machine (Mindray, Shenzhen, 
P. R. China), with a probe of $12 \mathrm{mHz}$ frequency. Diaphragmatic ultrasonography was performed with the patient placed in a supine position. The ultrasound probe was placed in the axillary midline from $\mathrm{T} 4$ and was guided caudally to identify the three lines corresponding to the diaphragm. After they were located, a section was made in mode $\mathrm{M}$ and the maximum thickness and minimum thickness of this muscle were measured. Once the measures were obtained, the TF was calculated using the formula described in previous studies: [(inspiratory thickness - expiratory thickness)/expiratory thickness] $[16,21]$. Bilateral ultrasonography of the diaphragm was performed.

TF was measured in normal breathing and forced inspiration, and measurements were performed on both hemidiaphragms. For the measurement in forced inspiration, the patient was asked to perform a deep inspiratory effort at maximum capacity, and the fraction was calculated in patients capable of performing the inspiratory effort at maximum capacity. This process was repeated three times with a minute difference and the average TF was obtained. Diaphragmatic dysfunction was considered as a TF of less than $20 \%[16,21,25]$.

A descriptive study of the variables was performed by calculating the central tendency and dispersion measures for the quantitative variables and the exact calculation and the percentage for the qualitative variables. The comparison between patients with diaphragmatic dysfunction and no diaphragmatic dysfunction was performed using the Wilcoxon signed rank test. The comparison of the categorical variables between two or more subgroups was performed using the Pearson's chisquared test or, if appropriate, Fisher's exact test. The independent effect of the clinical variables was calculated using a binary multivariate logistic regression model, considering as a dependent variable the overall incidence of respiratory involvement. The Hosmer-Lemeshow goodness-of-fit test was used to assess the overall fit of the model. The variables included in the multivariate analyses, in addition to age, the administration of reperfusion treatments and COPD, were those with statistical significance at $p \leq 0.05$ in the bivariate models. Odds ratios (OR) were calculated for each variable. To analyse the cut-off point with the best discriminative value of the quantitative variables, ROC (Receiver Operating Characteristic) curve analysis was conducted. A value of $p \leq 0.05$ was considered significant throughout the study. All the results were analysed with the IBM SPSS Statistics ${ }^{\bullet}$ software Version 19 (SPSS, Chicago, IL, US).

\section{Ethics}

It is an observational, non-interventional study, the ultrasonographic data obtained were not used for modification of the standard treatment regimens. The authors of the research asked all patients to sign an informed consent form prior to undergoing diaphragmatic ultrasonography. Good clinical practice guidelines and the declaration of Helsinki were followed. Confidentiality of the data obtained was kept and they were only used for the study purposes. Our clinical research was reviewed and approved by the Clinical Research Ethics committee of the University Hospital Complex of Albacete, and was approved on 17 October 2017 with act number 09/2017.

\section{Results}

During the study period a total of 160 patients with a diagnosis of stroke were admitted, including ischaemic, haemorrhagic and vertebrobasilar stroke. The study subjects were recruited consecutively reaching a total of 72 patients. The final cohort comprises 60 patients, as 12 patients were rejected for not meeting accurately the inclusion criteria ( 9 cases infratentorial ischaemic stroke, 2 for history of thoracic trauma and 1 patient for a history of liver surgery). The demographic data and the history of the patient are given in Table 1 .

\section{Table 1 Demographic data and the history of the patient}

\begin{tabular}{|c|c|}
\hline Age & 69.30 years \pm 9.66 years \\
\hline Sex & $51.7 \%(n=31)$ male \\
\hline Arterial hypertension & $63.3 \%(n=38)$ \\
\hline Dyslipidaemia & $46.7 \%(n=28)$ \\
\hline Diabetes mellitus & $30 \%(n=18)$ \\
\hline \multirow[t]{2}{*}{ Smoking } & $66.7 \%(n=40)$ no smoking \\
\hline & $16.7 \%(n=10)$ former smoker \\
\hline COPD & $6.7 \%(n=4)$ \\
\hline SAHS & $10 \%(n=6)$ \\
\hline \multirow[t]{2}{*}{ Dyspnoea } & $84.7 \%(n=50)$ Grade 0 \\
\hline & $10.2 \%(n=6)$ Grade 1 \\
\hline \multirow[t]{2}{*}{ NYHA scale } & $60 \%(n=36)$ Class 1 \\
\hline & $35 \%(n=21)$ Class 2 \\
\hline \multirow[t]{5}{*}{ Vascular territory affected } & Small vessel 19 (31.7\%) \\
\hline & ACA 4 (6.66\%) \\
\hline & MCA 32 (53.33\%) \\
\hline & PCA 4 (6.66\%) \\
\hline & Carotid 1 (1.66\%) \\
\hline $\mathrm{NIHSS}$ & $3(2-6)$ \\
\hline \multirow[t]{4}{*}{ Reperfusion therapies } & $58.3 \%(n=35)$ No therapy \\
\hline & $20 \%(n=12)$ Thrombolysis \\
\hline & $18.3 \%(n=11)$ Thrombectomy \\
\hline & $3.3 \%(n=2)$ Both therapies \\
\hline
\end{tabular}

ACA Anterior cerebral artery, COPD Chronic Obstructive Pulmonary Disease, MCA Middle cerebral artery, NIHSS National institute of Health Stroke Scale, NYHA New York Heart Association, PCA Posterior cerebral artery, SAHS Sleep Apnoea-Hypopnoea Syndrome 
The overall incidence of diaphragmatic dysfunction in acute ischaemic stroke in the first $48 \mathrm{~h}$ following admission was $51.7 \%$. An incidence of diaphragmatic dysfunction of $51.7 \%$ was seen under normal breathing and of $11.5 \%$ under forced breathing, with a statistically significant difference $(p<0.0001)$. Figure 1 details the differences between basal breathing and forced breathing.

\section{Diaphragmatic dysfunction under basal breathing}

Diaphragmatic dysfunction was seen on the side contralateral to the lesion in $51.7 \%(n=31)$ vs $1.7 \%(n=1)$ on the ipsilateral side $(p<0.0001)$. The median TF was $19 \%$ [12-43\%] on the contralateral side vs $37 \%$ [33-51\%] on the ipsilateral side $(\mathrm{p}<0.0001)$.

\section{Diaphragmatic dysfunction under forced breathing}

Diaphragmatic dysfunction was seen on the side contralateral to the lesion in $11.5 \%(n=6)$, while on the ipsilateral side no dysfunction was seen in any patient $(p=0.014)$. The median TF was $38 \%$ [27-72\%] on the contralateral side vs $75 \%$ [55-85\%] on the ipsilateral side $(p<0.0001)$.

Patients with diaphragmatic dysfunction had a higher degree of hemiparesis and a higher score on the NIHSS scale, in particular those with a NIHSS score $\geq 6(68 \%$ vs $24 \%, p=0.023)$. With regard to the vascular territory involved, $62.5 \%$ of the patients with stroke due to occlusion of the middle cerebral artery had diaphragmatic dysfunction (Table 2).

On the other hand, there was no statistically significant difference between diaphragmatic dysfunction and the reperfusion treatment performed (Table 3).

Diaphragmatic dysfunction in basal breathing in the side contralateral to the brain injury was associated with RI (severe dyspnoea, orthopnoea, respiratory infection or difficulty expectorating) in the first 6 months after the stroke, with statistically significant differences to the patients with normal TF (70\% vs $30 \%$, $p=0.002$ ) (Table 4).

This association was observed in the bivariate analysis with the TF reduction both under normal $(p=0.006)$ and forced breathing $(p=0.003)$, and also with the female sex $(p=0.011)$, smoking $(p=0.028)$, cardioembolic origin $(p=0.025)$, hemiparesis degree $(p<0.001)$ or the score of the degree in the NIHSS scale $(p=0.001)$ (Table 5).

The bivariate analysis relating the characteristics of the patients with mortality at 6 months of study is summarised in Table 6:

The multivariate analysis evidenced that the degree of hemiparesis $(\mathrm{OR}=0.015 ; 95 \% \mathrm{CI} 0.001-0.227 ; p=0.002)$,

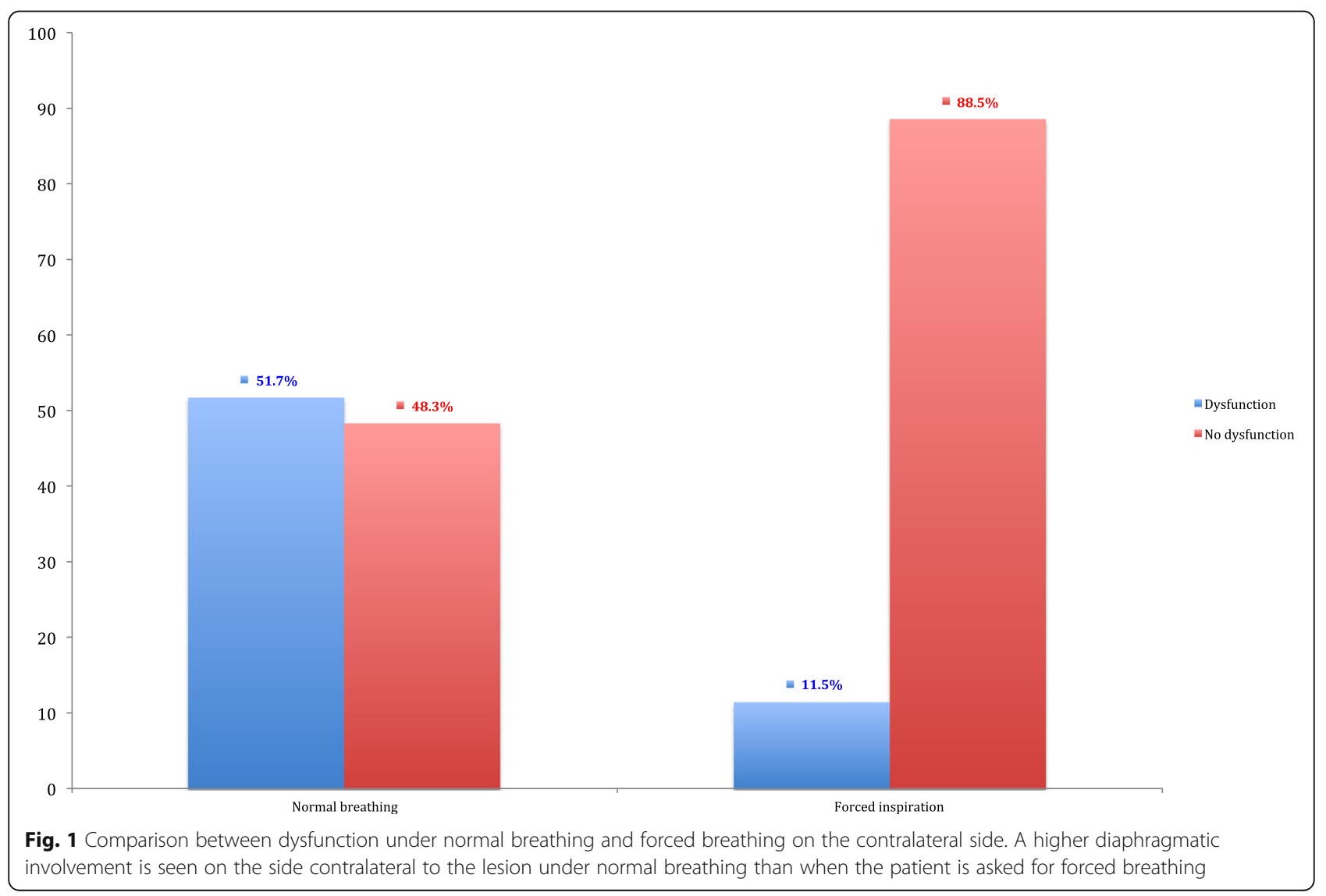


Table 2 Diaphragmatic dysfunction in normal and forced breathing according to the clinical examination

\begin{tabular}{lllll}
\hline & \multicolumn{2}{l}{ Normal breathing $(n=60)$} & & Forced breathing $(n=52)$ \\
\cline { 5 - 5 } & Dysfunction & No dysfunction & & No dysfunction \\
\hline NIHSS & $14(40 \%)$ & $21(60 \%)$ & $2(6 \%)$ & $31(94 \%)$ \\
NIHSS 0-6 & $6(50 \%)$ & $6(50 \%)$ & $3(30 \%)$ & $7(70 \%)$ \\
NIHSS 7-15 & $11(85 \%)$ & $2(15 \%)$ & $1(11 \%)$ & $8(89 \%)$ \\
NIHSS $\geq 16$ & & & 0 \\
Hemiparesis degree in the MRC scale & 0 & 0 & $1(50 \%)$ & $1(50 \%)$ \\
0 & $6(100 \%)$ & 0 & $3(50 \%)$ & $3(50 \%)$ \\
1 & $6(100 \%)$ & 0 & $2(20 \%)$ & $8(80 \%)$ \\
2 & $10(100 \%)$ & 0 & 0 & $11(100 \%)$ \\
4 & $6(54.5 \%)$ & $5(45.5 \%)$ & 0 & $23(100 \%)$ \\
\hline
\end{tabular}

The table shows the relationship between diaphragmatic dysfunction and the NIHSS score and the degree of hemiparesis according to the MRC scale of muscle strength

MRC Medical Research Council, NIHSS National Institute of Health Stroke

diaphragmatic dysfunction (OR $=1.095$; 95\% CI 1.0951.186; $p=0.026)$ and female sex $(\mathrm{OR}=248.312$; $95 \% \mathrm{CI}$ 7.02-8718.144; $\mathrm{p}=0.002)$ were independent predictive factors of RI (Table 7).

With regard to the diaphragmatic dysfunction shown by ultrasound, the maximum point of maximum diagnostic precision (sensitivity vs specificity) of the TF for the incidence of severe respiratory symptoms is plotted in a ROC curve (Fig. 2), resulting in a cut-off point with a higher AUC (area under the curve) of 24\% (AUC 0.73; CI 0.6$0.86, p=0.003$ ), with sensitivity results of $75.7 \%$, specificity of $62.9 \%$, positive predictive value of $71.4 \%$, negative predictive value of $68 \%$ and validity index of $70 \%$.

\section{Discussion}

This is the first study to evaluate the incidence of diaphragmatic dysfunction in acute supratentorial stroke, obtaining an overall incidence of $51.7 \%$. This diaphragmatic dysfunction is seen mainly on the side contralateral to the brain injury, where dysfunction is seen in $51.7 \%$ of the cases vs $1.7 \%$, where it is seen on the ipsilateral side. Under forced breathing, the increased inspiratory effort reduced the incidence of diaphragmatic dysfunction to $11.5 \%$. The previous studies evaluating diaphragmatic dysfunction in stroke were performed in patients with hemiparesis and none early after the diagnosis $[1,26]$. In 1988. Santamaría and Ruiz [27] observed diaphragmatic dysfunction in 62 patients with recent hemiparesis due to supratentorial stroke after comparing the chest X-rays of these patients to those of subjects with brain diseases. Subsequently, in 1994, Cohen et al. [28] reported similar results in patients with hemiparesis between 9 days and 14 months before.

Table 3 Reperfusion techniques and diaphragmatic dysfunction

\begin{tabular}{lllll}
\hline & \multicolumn{2}{l}{ Normal breathing $(\mathrm{n}=60)$} & & \multicolumn{2}{l}{ Forced breathing $(n=52)$} \\
\cline { 2 - 4 } & Dysfunction & No dysfunction & $3(9.7 \%)$ & No dysfunction \\
\hline No therapy & $17(48.6 \%)$ & $18(51.4 \%)$ & $2(20 \%)$ & $8(90.3 \%)$ \\
Thrombolysis & $6(50 \%)$ & $6(50 \%)$ & $1(100 \%)$ & 0 \\
TIBI 2 & $2(100 \%)$ & 0 & $1(25 \%)$ & $3(75 \%)$ \\
TIBI 3 & $1(25 \%)$ & $3(75 \%)$ & 0 & 0 \\
TIBI 4 & $1(100 \%)$ & 0 & 0 & $5(100 \%)$ \\
TIBI 5 & $2(40 \%)$ & $3(60 \%)$ & $1(11 \%)$ & $8(89 \%)$ \\
Thrombectomy & $8(73 \%)$ & $3(17 \%)$ & $1(50 \%)$ & $1(50 \%)$ \\
TICl 2b & $2(66.7 \%)$ & $1(33.3 \%)$ & 0 & $9(100 \%)$ \\
TICl 3 & $6(60 \%)$ & $4(40 \%)$ & 0 & $2(100 \%)$ \\
Dual therapy & 0 & $2(100 \%)$ & &
\end{tabular}

TIBI Thrombolysis in Brain Ischaemia, TICI Thrombolysis in Cerebral Infarction. 
Table 4 Respiratory impairment and diaphragmatic dysfunction

\begin{tabular}{|c|c|c|c|c|}
\hline & \multicolumn{2}{|c|}{ Normal breathing* $(n=60)$} & \multicolumn{2}{|c|}{ Forced breathing** $(n=52)$} \\
\hline & Dysfunction & No dysfunction & Dysfunction & No dysfunction \\
\hline No respiratory impairment & $8(30 \%)$ & 19 (70\%) & $1(4 \%)$ & $25(96 \%)$ \\
\hline $\begin{array}{l}\text { Respiratory impairment } \\
\text { - Dyspnoea }(n=21,35 \%) \\
\text { - Orthopnoea }(n=7,11 \%) \\
\text { - Respiratory infection }(n=14,23 \%) \\
\text { - DE }(n=22,36 \%)\end{array}$ & $23(70 \%)$ & $10(30 \%)$ & $5(19 \%)$ & $21(81 \%)$ \\
\hline
\end{tabular}

The table shows the association between diaphragmatic dysfunction and respiratory impairment. The last file shows the incidence of appearance of each symptom during the 6 months of follow-up ${ }^{*} p=0.002 .{ }^{* *} p=0.191$ $D E$ Difficulty expectorating

The relationship existing between diaphragmatic dysfunction and ischaemic stroke can be explained both by the change in the voluntary function of the diaphragm due to a lesion in the corticospinal tract and by the lack of automatic control through the bulbospinal tract $[5,6]$. However, other studies have suggested that the involvement of the diaphragm in stroke may be due to a disorder in the corticodiaphragmatic pathways [29]. Using magnetic stimulation techniques, it has been seen that the response of the diaphragm to stimulation of a single brain hemisphere is mainly contralateral, and there is a lower response in the ipsilateral side [30]. This response in the ipsilateral side is explained by the presence of small cross connections between the two phrenic nerves, resulting in bilateral innervation of the diaphragm [29].
These connections were also studied in patients with unilateral diaphragmatic dysfunction that show dyspnoea, where an impairment is seen in the pressure generated by the theoretically healthy diaphragm [31].

Diaphragmatic dysfunction is not a disease commonly diagnosed, in particular in the case of an unilateral injury [32]. In our study we used ultrasonography to make the diagnosis of diaphragmatic dysfunction, through the analysis of the TF. The study of lung and diaphragmatic function by ultrasonography was characterised by Khedr et al. in 2000 [5] and Jung et al. in 2014 [6] who observed a correlation between clinical motor deficit in patients with hemiparesis and the hemidiaphragmatic excursion on the side ipsilateral to the hemiparesis. Ultrasonography is a technique with advantages derived

Table 5 Respiratory impairment and characteristics of the patients

\begin{tabular}{|c|c|c|c|}
\hline & Disorder n (\%) & No disorder n (\%) & $p$ \\
\hline Female sex & $12(38.7)$ & $19(61.3)$ & 0.011 \\
\hline Hypertension & $21(55.3)$ & $17(44.7)$ & 0.957 \\
\hline Dyslipidaemia & $16(57.1)$ & $15(46.9)$ & 0.755 \\
\hline Diabetes & $12(66.7)$ & $6(33.3)$ & 0.234 \\
\hline Smoking & $7(35)$ & $13(65)$ & 0.028 \\
\hline Poor performance status & $13(54.2)$ & $11(45.8)$ & 0.916 \\
\hline Previous severe dyspnoea & $3(100)$ & $0(0)$ & 0.245 \\
\hline COPD & $3(75)$ & $1(25)$ & 0.620 \\
\hline SAHS & $1(16.7)$ & $5(83.3)$ & 0.081 \\
\hline Previous severe hemiparesis & $1(100)$ & $0(0)$ & 1 \\
\hline Cardioembolic origin & $19(45.2)$ & $23(54.8)$ & 0.025 \\
\hline Sensory aphasia & $5(100)$ & $0(0)$ & 0.058 \\
\hline Reperfusion treatment & $15(60)$ & $10(40)$ & 0.511 \\
\hline Hemiparesis, severe & $12(100)$ & $0(0)$ & $<0.001$ \\
\hline Age, mean $\pm S D$ & $69.5 \pm 10.5$ & $69.1 \pm 8.8$ & 0.872 \\
\hline NIHSS, median [25\%:75\%] & 9 [3.5:18.5] & $4[2: 6]$ & 0.001 \\
\hline TF basal breathing $\%$, mean \pm SD & $21.1 \pm 17.2$ & $34.3 \pm 18.8$ & 0.006 \\
\hline TF forced inspiration $\%$, mean \pm SD & $37.9 \pm 21$ & $57.9 \pm 25.3$ & 0.003 \\
\hline
\end{tabular}

The table shows the association between respiratory impairment and the demographic and clinical characteristics of the patients. The statistically significant results are shown in bold

COPD Chronic Obstructive Pulmonary Disease, IQ Interquartile range, NIHSS National Institutes of Health Stroke Scale, SAHS Sleep Apnoea Hypopnea Syndrome, SD Standard desviation, TF Thickening fraction 
Table 6 Mortality and mRS and characteristics of the patients

\begin{tabular}{|c|c|c|c|c|c|c|}
\hline & \multicolumn{3}{|l|}{ Mortality } & \multicolumn{3}{|l|}{$\mathrm{mRS}$} \\
\hline & Mortality n (\%) & No n (\%) & $\mathrm{p}$ & Good pr. n (\%) & Poor pr. n (\%) & $\mathrm{p}$ \\
\hline Female sex & $3(10.3)$ & $26(89.7)$ & 0.666 & $19(65.5)$ & $10(34.5)$ & 0.855 \\
\hline Hypertension & $4(10.5)$ & $34(89.5)$ & 0.643 & $23(60.5)$ & $15(39.5)$ & 0.185 \\
\hline Dyslipidaemia & $3(10.7)$ & $25(89.3)$ & 0.533 & $17(60.7)$ & $11(39.3)$ & 0.360 \\
\hline Diabetes & $3(16.7)$ & $15(83.3)$ & 0.154 & $10(55.6)$ & $8(44.4)$ & 0.232 \\
\hline Smoking & 0 & $20(100)$ & 0.099 & $18(90)$ & $2(10)$ & 0.008 \\
\hline Poor performance status & $3(12.5)$ & $21(87.5)$ & 0.380 & $14(58.3)$ & $10(41.7)$ & 0.264 \\
\hline Previous severe dyspnoea & 0 & $3(100)$ & 1 & $1(33.3)$ & $2(66.7)$ & 0.255 \\
\hline COPD & 0 & $4(100)$ & 1 & $2(50)$ & $2(50)$ & 0.595 \\
\hline SAHS & 0 & $6(100)$ & 1 & $4(66.7)$ & $2(33.3)$ & 1 \\
\hline Cardioembolic origin & 0 & $42(100)$ & 0.002 & $32(76.2)$ & $10(23.8)$ & 0.034 \\
\hline Sensory aphasia & $1(20)$ & $4(80)$ & 0.363 & 0 & $5(100)$ & 0.003 \\
\hline Reperfusion treatment & $3(12)$ & $22(82)$ & 0.640 & $15(60)$ & $10(40)$ & 0.412 \\
\hline Severe hemiparesis & $1(2.1)$ & $47(97.9)$ & 0.004 & $38(79.2)$ & $10(20.8)$ & $<0.001$ \\
\hline Age, mean $\pm S D$ & $69.5 \pm 10.5$ & $68.9 \pm 9.4$ & 0.872 & $67.2 \pm 8.9$ & $73.4 \pm 10.1$ & 0.288 \\
\hline NIHSS, median [25\%:75\%] & 21 [18.5:24] & $4[3: 9]$ & $<0.001$ & $4[2: 8]$ & $10[5: 20]$ & 0.006 \\
\hline TF basal breathing $\%$, mean \pm SD & $0.14 \pm 0.04$ & $0.28 \pm 0.19$ & $<0.001$ & $0.31 \pm 0.20$ & $0.19 \pm 0.13$ & 0.004 \\
\hline TF forced inspiration $\%$, mean \pm SD & $0.40 \pm 0.06$ & $0.48 \pm 0.25$ & 0.143 & $0.51 \pm 0.26$ & $0.40 \pm 0.20$ & 0.061 \\
\hline Mortality & - & - & - & 0 & $5(100)$ & 0.003 \\
\hline $\mathrm{Rl}$ & $5(8.3)$ & $28(84.8)$ & 0.043 & $17(51.7)$ & $16(48.5)$ & 0.007 \\
\hline
\end{tabular}

The table shows the association between mortality and mRS at 3 months and the demographic and clinical characteristics of the patients. The statistically significant results are highlighted in bold

COPD Chronic Obstructive Pulmonary Disease, IQ Interquartile range, mRS Modified Rankin Scale, NIHSS National Institutes of Health Stroke Scale, pr Prognosis, RI Respiratory impairment, SAHS Sleep Apnoea-Hypopnoea Syndrome, SD Standard deviation, TF Thickening fraction

from its non-invasive nature, being performed at the bedside of the patient [33] and with no involvement of radiation [22]. In addition, it allows images to be viewed in real time and analyse the muscle independently from the effort of the patient [16, 17, 23]. Using this technique, the diaphragm can be seen as two hyperechogenic layers corresponding to the peritoneal wall and the pleural wall together with an intermediate hypoechoic line corresponding to the muscle itself [16].

Upon breathing, the diaphragm contracts and this results in a muscle thickening proportional to contraction [34]. Therefore, diaphragmatic function can be evaluated by the analysis of thickening of the diaphragm during its contraction, which corresponds to the TF [16]. Although other studies previously measured the diaphragmatic excursion $[5,6]$, in our case he have studied the TF due to the difficult evaluation of the left window that is obtained with the low-frequency probe necessary for the measurement of excursion [9, 32, 35]. In addition, diaphragmatic excursion reflects the inspiratory volume which, in turn, may be influenced by participation of the accessory muscles, responsible for $20 \%$ of the respiratory effort $[5,9,10]$.
The sample analysis allowed us to observe that the appearance of diaphragmatic dysfunction occurs mainly in patients with stroke in the territory of the middle cerebral artery, in patients with a score above 6 points on the NIHSS scale (68 vs $24 \%, p=0.023$ ) and in patients with hemiparesis $(p=0.01)$. It must be highlighted that $23 \%$ of the patients with diaphragmatic dysfunction do now show muscle weakness $(p<0.001)$. This may be because corticospinal pathway involvement can be variable and dependent on the stroke territory [36]. With regard to the administration of reperfusion treatments or their result, we have not found any significant relationship with the development of diaphragmatic dysfunction.

The clinical impact of diaphragmatic dysfunction in stroke is still to be elucidated. However, the appearance of respiratory symptoms has been described as a form of presentation of diaphragmatic dysfunction [37]. The TF reduction can be related to a reduction in pulmonary volumes that predispose to respiratory infection [38], as well as a reduction in the inspiratory flow during coughing that limits effective cough [39]. In addition, diaphragmatic dysfunction is related to the appearance of orthopnoea and dyspnoea, frequently underdiagnosed [14]. In our series, $55 \%$ of the patients with diaphragmatic dysfunction developed SRI 
Table 7 Multivariate analysis of respiratory impairment

\begin{tabular}{|c|c|c|c|c|}
\hline \multirow[t]{2}{*}{ Variables } & \multirow[t]{2}{*}{ OR } & \multicolumn{2}{|c|}{$\mathrm{Cl}=95 \%$ for $\mathrm{OR}$} & \multirow[t]{2}{*}{$p$} \\
\hline & & Upper & Lower & \\
\hline Age & 0.945 & 0.828 & 1.079 & 0.404 \\
\hline Sex & 248.312 & 7.072 & 8718.144 & 0.002 \\
\hline SAHS & $<0.001$ & & & 0.999 \\
\hline Cardioembolic stroke & 0.049 & 0.001 & 2.151 & 0.118 \\
\hline COPD & $2.276[10]$ & & & 0.999 \\
\hline Aphasia & 1.324 [13] & & & 0.998 \\
\hline Reperfusion treatment & 0.142 & 0.006 & 3.535 & 0.234 \\
\hline Post-stroke hemiparesis & 0.015 & 0.001 & 0.227 & 0.002 \\
\hline NIHSS & 0.878 & 0.692 & 1.114 & 0.285 \\
\hline Contralateral TF & 1.095 & 1.011 & 1.186 & 0.026 \\
\hline Constant & $2.183[8]$ & & & 0.004 \\
\hline
\end{tabular}

The statistically significant results are highlighted in bold

CI Confidence interval, COPD Chronic Obstructive Pulmonary Disease, NIHSS National Institutes of Health Stroke Scale, OR Odds Ratio, SAHS Sleep Apnoea Hypopnoea Syndrome, TF Thickening fraction

during the the first 6 months of follow-up. The reduction of contralateral TF in basal breathing was also related independently to the RI described (severe dyspnoea, orthopnoea, respiratory infection or difficulty expectorating) $(\mathrm{OR}=1.095 ; 95 \%$ CI 1.095-1.186; $p=0.026)$, with a diagnostic precision of $73 \%(p=0.003$, CI $0.6-0.86)$, and the maximum precision value found was $24 \%$. Other authors have considered a value of $20 \%$ as a cut-off point for the diagnosis of diaphragmatic dysfunction [25], as in this study, but we do not know any study that describes a predictive value of respiratory impairment. Other factors related independently to RI were the degree of hemiparesis
$(\mathrm{OR}=0.015 ; 95 \% \mathrm{CI} 0.001-0.227 ; p=0.002)$ and female sex $(\mathrm{OR}=248.312$; 95\% CI 7.02-8718.144; $\mathrm{p}=0.002)$. It seems logical to consider that a higher degree of hemiparesis will also be associated with a greater diaphragmatic dysfunction, potentially explaining this finding, though we have not measured its severity. The finding of female sex as a predictive factor could be justified by the anatomic variations, including a smaller diaphragm that could account for a reduction of up to $20 \%$ in the expansion capacity [ 40 , 41]. The evaluation of the diaphragmatic function after an ischaemic stroke could have potential clinical consequences. Development of respiratory failure,

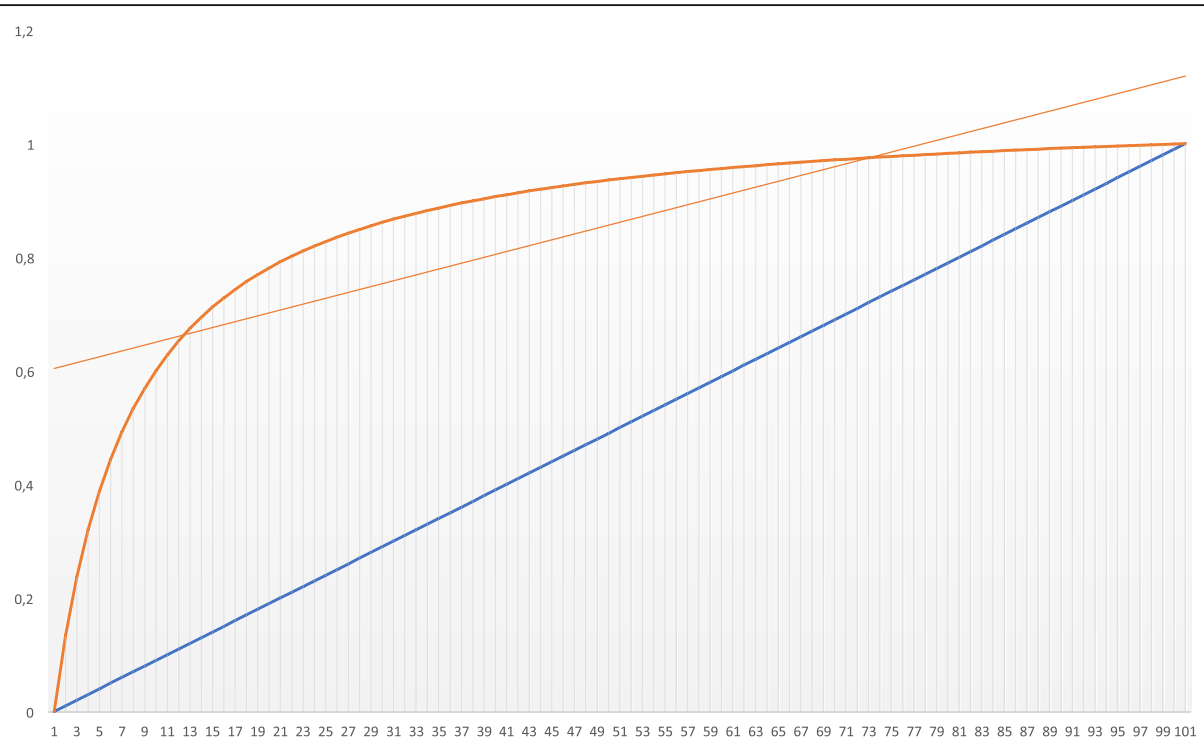

Fig. 2 Receiver Operating Characteristic curve: Figure shows the diagnostic accuracy of diaphragmatic ultrasound respect the respiratory impairment. It shows an Area Under Cover of $73 \%(p=0.003)$, a sensitivity of $75.7 \%$ and a specificity of $62.9 \%$. The graphic has been obtained using Excel 2019 (Microsoft Corporaton Redmond, Washington, United States) 
atelectasis and respiratory infections has been described, as well as a reduction in the cough reflex in these patients [37]. In addition, the early diagnosis of this dysfunction could reinforce rehabilitation treatment for the purpose of improving recovery of respiratory function in these patients. Furthermore, we observed a significant relationship between decreased TF and the prognosis, both with mortality and $\mathrm{mRS}$.

Our study sample comprised 60 patients. As it is a pilot study, the sample has been sufficient to obtain the incidence of diaphragmatic dysfunction. However, when dividing the sample into subgroups we found limitations in some comparisons and could not achieve statistical significance, despite noticing a clinical tendency to the differences observed between subgroups. In addition, the limitation for performing deep breathing in some patients has limited the sample number even further in this group. We have not found any study confirming the need to calculate the TF in more than one cycle; however, we have decided to average 3 cycles to avoid possible differences between each of them. A limitation common in many of the studies is the subsequent reproducibility and the within-observer variability that can exist in the same test. It must be noted that withinobserver variability, despite being limited in the TF [42], has been removed in our case as all ultrasonographies were performed by the same observer [43].

\section{Conclusions}

The incidence of diaphragmatic dysfunction in patients with supratentorial ischaemic stroke in the first $48 \mathrm{~h}$ is high (51.7\%). Considering its potential clinical implications, studies are required to evaluate the incidence of respiratory complications in these patients, as well as the impact of respiratory rehabilitation in the clinical prognosis.

\section{Abbreviations \\ ACA: Anterior cerebral artery; AUC: Area Under Cover; COPD: Chronic Obstructive Pulmonary Disease; CT: Computerised Tomography; DE: Difficulty expectorating; MCA: Middle cerebral artery; MRC: Medical Research Council; mRS: Modified Rankin Scale; MT: Mechanical Thrombectomy; NIHSS: National Institute of Health Stroke Scale; NYHA: New York Heart Association; OR: Odds Ratio; PCA: Posterior cerebral artery; RI: Respiratory Impairment; ROC: Receiver Operating Characteristic; SAHS: Sleep Apnoea-Hypopnoea Syndrome; TIBI: Thrombolysis in Brain Ischemia; TICl: Thrombolysis in cerebral infarction; TF: Thickening fraction}

\section{Acknowledgments}

Pablo Cuesta for his involvement in the clinical management of the patients. Manuel Gerónimo for statistical advice, and Jav Ahmad for the revision of the English translation. We thank all patients and their families for generously consenting to use the data in this research.

\section{Authors' contributions}

JVC carried out the diaphragmatic exploration, interpreted the patient data and was a major contributor in writing the manuscript. JAM supervised the data collection and review the manuscript. FHF was responsible for the diagnosis and neurological management of the patients, carried out the neurointerventional procedures and review the manuscript. All authors read and approved the final manuscript.

Funding

Not applicable.

\section{Availability of data and materials}

The datasets used and/or analysed during the current study are available from the corresponding author on reasonable request.

\section{Ethics approval and consent to participate}

Our clinical research was reviewed and approved by the Clinical Research Ethics committee of the University Hospital Complex of Albacete, and was approved on 17 October 2017 with act number 09/2017. We explain the diaphragmatic ultrasound and obtained patient written consent for their clinical information and diaphragmatic exploration.

\section{Consent for publication}

Not applicable.

\section{Competing interests}

The authors declare that they have no competing interests.

\section{Author details}

${ }^{1}$ Department of Anesthesiology and Critical Care Medicine, Complejo Hospitalario Universitario de Albacete, Albacete, Spain. ${ }^{2}$ Department of Neurology, Unit of Interventional Neuroradiology, Complejo Hospitalario Universitario de Albacete, Albacete, Spain.

Received: 21 November 2019 Accepted: 27 February 2020

Published online: 05 March 2020

\section{References}

1. Kumar S, Reddy R, Prabhakar S. Contralateral diaphragmatic palsy in acute stroke: an interesting observation. Indian J Crit Care Med. 2009;13:28-30..

2. Man S, Schold JD, Uchino K. Impact of stroke center certification on mortality after ischemic stroke: the Medicare cohort from 2009 to 2013. Stroke. 2017:48:2527-33.

3. Martínez-Vila E, Murie Fernández M, Pagola I, Irimia P. Enfermedades cerebrovasculares. Medicine. 2011;10:4871-81.

4. Rochester CL, Mohsenin V. Respiratory complications of stroke. Semin Respir Crit Care Med. 2002:23:248-60

5. Khedr EM, El Shinawy O, Khedr T, Aziz Ali YA, Awad EM. Assessment of corticodiaphragmatic pathway and pulmonary function in acute ischemic stroke patients. Eur J Neurol. 2000;7:323-30.

6. Jung KJ, Park JY, Hwang DW, Kim JH, Kim JH. Ultrasonographic diaphragmatic motion analysis and its correlation with pulmonary function in hemiplegic stroke patients. Ann Rehabil Med. 2014;38:29-37.

7. Li L, Zhang LH, Xu WP, Hu JM. Risk assessment of ischemic stroke associated pneumonia. World J Emerg Med. 2014:5:209-13.

8. Jandt SR, Caballero RM, Junior LA, Dias AS. Correlation between trunk control, respiratory muscle strength and spirometry in patients with stroke: an observational study. Physiother Res Int. 2011;16:218-24.

9. Gerscovich EO, Cronan M, McGahan JP, Jain K, Jones CD, McDonald C. Ultrasonographic evaluation of diaphragmatic motion. J Ultrasound Med. 2001;20:597-604.

10. Noh DK, Lee JJ, You JH. Diaphragm breathing movement measurement using ultrasound and radiographic imaging: a concurrent validity. Biomed Mater Eng. 2014:24:947-52

11. de la Quintana Gordon FB, Nacarino Alcorta B, Fajardo PM. Valoración ecográfica de la función diafragmática y sus aplicaciones en el paciente crítico, en ventilación mecánica y en la anestesia del plexo braquial. Rev Esp Anestesiol Reanim. 2017;64:513-21

12. Kocjan J, Adamek M, Gzik-Zroska B, Czyżewski D, Rydel M. Network of breathing. Multifunctional role of the diaphragm: a review. Adv Respir Med. 2017:85:224-32.

13. MacBruce D, Safdar S, Katpally K, Shaaban H, Adelman M. Idiopathic bilatera diaphragmatic dysfunction as a cause of dyspnea. Lung India. 2016;33:3302.

14. McCool FD, Tzelepis GE. Dysfunction of the diaphragm. N Engl J Med. 2012; 366:932-42 
15. Bonnevie T, Gravier FE, Ducrocq A, Debeaumont D, Viacroze C, Cuvelier A, et al. Exercise testing in patients with diaphragm paresis. Respir Physiol Neurobiol. 2018;248:31-5.

16. Summerhill EM, El-Sameed YA, Glidden TJ, McCool FD. Monitoring recovery from diaphragm paralysis with ultrasound. Chest. 2008;133:737-43.

17. Boon AJ, Harper CJ, Ghahfarokhi LS, Strommen JA, Watson JC, Sorenson EJ. Two-dimensional ultrasound imaging of the diaphragm: quantitative values in normal subjects. Muscle Nerve. 2013;47:884-9.

18. Shinohara S, Yamada T, Ueda M, Ishinagi H, Matsuoka T, Nagai S, et al. Phrenic nerve reconstruction and bilateral diaphragm plication after lobectomy. Ann Thorac Surg. 2017;104:9-11.

19. Houston JG, Morris AD, Grosset DG, Lees KR, McMillan N, et al. Ultrasonic evaluation of movement of the diaphragm after acute cerebral infarction. J Neurol Neurosurg Psychiatry. 1995;58:738-41.

20. Jung KM, Bang DH. Effect of inspiratory muscle training on respiratory capacity and walking ability with subacute stroke patients: a randomized controlled pilot trial. J Phys Ther Sci. 2017;29:336-9.

21. Boon AJ, Sekiguchi H, Harper CJ, Strommen JA, Ghahfarokhi LS, Watson JC, et al. Sensitivity and specificity of diagnostic ultrasound in the diagnosis of phrenic neuropathy. Neurology. 2014;30:1264-70.

22. Noda Y, Sekiguchi K, Kohara N, Kanda F, Toda T. Ultrasonographic diaphragm thickness correlates with compound muscle action potential amplitude and forced vital capacity. Muscle Nerve. 2016;53:522-7.

23. Tsui JJ, Tsui BC. A novel systematic ABC approach to diaphragmatic evaluation (ABCDE). Can J Anaesth. 2016:63:636-7.

24. Alonso de Leciñana M, Egido JA, Casado I, Ribó M, Dávalos A, Masjuan J, et al. Guidelines for the treatment of acute ischaemic stroke. Neurologia. 2014;29:102-22.

25. Dres M, Dubé BP, Mayaux J, Delemazure J, Prodanovic $H$, Similowski T, et al. Reliability of diaphragmatic ultrasonography to detect diaphragm dysfunction in critically ill patients. Intensive Care Med Exp. 2015;3:A452.

26. Wu MN, Chen PN, Lai CL, Liou LM. Contralateral diaphragmatic palsy after subcortical middle cerebral artery infarction without capsular involvement. Neurol Sci. 2011;32:487-90

27. Santamaria J, Ruiz C. Diaphragmatic elevation in stroke. Eur Neurol. 1988;28: 81-3.

28. Cohen E, Mier A, Heywood P, Murphy K, Boultbee J, Guz A. Excursionvolume relation of the right hemidiaphragm measured by ultrasonography and respiratory airflow measurements. Thorax. 1994;49:885-9.

29. Similowski T, Catala M, Rancurel G, Derenne JP. Impairment of central motor conduction to the diaphragm in stroke. Am J Respir Crit Care Med. 1996; 154:436-41.

30. Maskill D, Murphy K, Mier A, Owen M, Guz A. Motor cortical representation of the diaphragm in man. J Physiol. 1991;443:105-21.

31. Caleffi-Pereira M, Pletsch-Assunção R, Cardenas LZ, Santana PV, Ferreira JG, lamonti VC, et al. Unilateral diaphragm paralysis: a dysfunction restricted not just to one hemidiaphragm. BMC Pulm Med. 2018;18:126.

32. Sarwal A, Walker FO, Cartwright MS. Neuromuscular ultrasound for evaluation of the diaphragm. Muscle Nerve. 2013;47:319-29.

33. Esper R, Talavante Y. Evaluación ultrasonográfica del diafragma en el enfermo grave. Rev Asoc Mex Med Crit y Ter Int. 2014;28:187-94.

34. Cohn D, Benditt JO, Eveloff S, McCool FD. Diaphragm thickening during inspiration. J Appl Physiol. 1997;83:291-6.

35. Scott S, Fuld JP, Carter R, McEntegart M, MacFarlane NG. Diaphragm ultrasonography as an alternative to whole-body plethysmog- raphy in pulmonary function testing. J Ultrasound Med. 2006;25:225-32.

36. Chamorro A, Marshall RS, Valls-Solé J, Tolosa E, Mohr JP. Motor behavior in stroke patients with isolated medial frontal ischemic infarction. Stroke. 1997; 28:1755-60.

37. Choi YM, Park GY, Yoo Y, Sohn D, Jang Y, Im S. Reduced diaphragm excursion during reflexive citric acid cough test in subjects with subacute stroke. Respir Care. 2017;62:1571-81.

38. Kim M, Lee K, Cho J, Lee W. Diaphragm thickness and inspiratory muscle functions in chronic stroke patients. Med Sci Monit. 2017;23: 1247-53.

39. Park GY, Kim SR, Kim YW, Jo KW, Lee EJ, Kim YM, et al. Decreased diaphragm excursion in stroke patients with dysphagia as assessed by $\mathrm{M}$ mode sonography. Arch Phys Med Rehabil. 2015;96:114-21.

40. Bellemare $F$, Jeanneret $A$, Couture J. Sex differences in thoracic dimensions and configuration. Am J Respir Crit Care Med. 2003;168:305-12.
41. Valenza MC, Martin-Martin L, Botella-Lopez M, Castellote-Caballero Y, Revelles-Moyano F, Serrano-Guzman M, et al. La función pulmonar, factores físicos que la determinan y su importancia para el fisioterapeuta. Rev Iberoam Fisioter Kinesiol. 2011;14:83-9.

42. Vivier E, Mekontso Dessap A, Dimassi S, Vargas F, Lyazidi A, Thille AW, et al. Diaphragm ultrasonography to estimate the work of breathing during noninvasive ventilation. Intensive Care Med. 2012;38:796-803.

43. Adams HP Jr, Davis PH, Leira EC, Chang KC, Bendixen BH, Clarke WR, et al. Baseline NIH stroke scale score strongly predicts outcome after stroke: a report of the trial of org 10172 in acute stroke treatment (TOAST). Neurology. 1999;53:126-31.

\section{Publisher's Note}

Springer Nature remains neutral with regard to jurisdictional claims in published maps and institutional affiliations.
Ready to submit your research? Choose BMC and benefit from:

- fast, convenient online submission

- thorough peer review by experienced researchers in your field

- rapid publication on acceptance

- support for research data, including large and complex data types

- gold Open Access which fosters wider collaboration and increased citations

- maximum visibility for your research: over $100 \mathrm{M}$ website views per year

At $\mathrm{BMC}$, research is always in progress.

Learn more biomedcentral.com/submissions 